\title{
Relationship between Antioxidant Components and Oxidative Stability of Peanut Oils as Affected by Roasting Temperatures
}

\author{
Jhih-Ying Ciou ${ }^{1}$, Hsin-Chun Chen ${ }^{2} \mathbb{D}$, Chih-Wei Chen ${ }^{3, *}$ and Kai-Min Yang ${ }^{4}(\mathbb{C}$ \\ 1 Department of Food Science, Tunghai University, Taichung 407, Taiwan; jyciou@thu.edu.tw \\ 2 Department of Cosmeceutics, China Medical University, Taichung 406, Taiwan; d91628004@ntu.edu.tw \\ 3 Bachelor Degree Program in Environment and Food Safety Laboratory Science, \\ Chang Jung Christian University, Tainan 71101, Taiwan \\ 4 Department of Hospitality Management, Mingdao University, Chang Hua 523, Taiwan; a9241128@gmail.com \\ * Correspondence: ccwlly@mail.cjcu.edu.tw
}

Citation: Ciou, J.-Y.; Chen, H.-C.; Chen, C.-W.; Yang, K.-M. Relationship between Antioxidant Components and Oxidative Stability of Peanut Oils as Affected by Roasting Temperatures. Agriculture 2021, 11, 300. https:// doi.org/10.3390/agriculture11040300

Academic Editor:

M. Luisa Hernández

Received: 22 February 2021

Accepted: 28 March 2021

Published: 31 March 2021

Publisher's Note: MDPI stays neutral with regard to jurisdictional claims in published maps and institutional affiliations.

Copyright: (c) 2021 by the authors. Licensee MDPI, Basel, Switzerland. This article is an open access article distributed under the terms and conditions of the Creative Commons Attribution (CC BY) license (https:/ / creativecommons.org/licenses/by/ $4.0 /)$.

\begin{abstract}
The study sought to investigate the effect of roasting temperatures on antioxidant components and oxidative stability of peanut oils. The total phenolic content, total flavonoid content, $\alpha$-tocopherol content, and phytosterol content in peanut oils was influenced by roasting at temperatures of $120^{\circ} \mathrm{C}, 140{ }^{\circ} \mathrm{C}$, and $160^{\circ} \mathrm{C}$, while those roasting temperatures had no effect on the fatty acid profile and $\gamma$-tocopherol content of peanut oils. Roasting promotes the quality of peanut oil aroma via the Maillard reaction, particularly when it is derived from $\mathrm{N}$-heterocyclic compounds (such as pyrazine and pyrrole). The oxidative stability of peanut oils was investigated using the Rancimat method, and the results show that there is a linear relationship between roasting and natural logarithm of the induction period $\left(\mathrm{R}^{2}: 0.959 \sim 0.998\right)$. This was determined based on the Arrhenius equation, which indicated the activation energy $\left(E_{\mathrm{a}}\right)$ was in the range of $82.08 \sim 108.61 \mathrm{~kJ} / \mathrm{mol}$. In principal component analysis (PCA) analysis, the antioxidant stability of the increase levels of phenols released in the peanut oils was found to rise with the increment of roasting temperatures. The data obtained in this study should be confirmed as the nutritional benefits of peanut oils that will be most appealing to consumers.
\end{abstract}

Keywords: peanut oils; roast; antioxidant; oxidative stability

\section{Introduction}

Oil-bearing crops include those whose fruits (or mesocarps), seeds, and nuts are valued for the edible or industrial oils extracted from them. The Food and Agriculture Organization of the United Nations (FAO) listed 21 oil crops, which collectively yield an annual production of world oilseed of about 100 million tons [1]. Vegetable oils have progressively supplanted animal oils as a major source of dietary fat, leading to oil crop production becoming one of the prevailing forms of world agriculture. Oil crops contain a diverse array that strengthens the nutritional value of the human diet, with the oils generated by such crops being especially good sources of tocopherol, thus promoting the balanced intake of vitamin E [1,2]. Peanut is most fundamental food crop in the world, and China, India, and the United States are the top three peanut producers worldwide [3]. Peanut pods ripen approximately 150 days after the seeds are planted. With mechanized reaping, the whole peanut plant, including the seed pods, are removed from the soil before being dried (sun or hot-air), and then seed shelling takes place [3,4]. Peanuts easily lipid oxidize and decompose during storage and transportation due to their high-fat levels $(>50 \%)$, and this influences their nutritional and agricultural value, and their edible safety [5-7].

The cooking methods used with edible oils differ in terms of the temperature, duration, and the amount of oil used. Vegetable oils are important constituents of the daily diet of most people, although the actual intake of such oils differs considerably depending 
on the cooking methods used. The World Health Organization (WHO) has identified three important factors for determining the nutritional value of oils: (I) the presence of antioxidants; (II) the ratio of saturated fatty acids (SFA), mono-unsaturated fatty acids (MUFA), and poly-unsaturated fatty acids (PUFA); and (III) the essential fatty acid ratio [8]. In relation to this, the WHO has recommended a ratio of 1:1.5:1 for SFA:MUFA:PUFA and a ratio of 1:5 10 for $\alpha$-linolenic acid (omega-3):linoleic acid (omega-6) in people's dietary intake. Vegetable oils are high in MUFA and, as part of a low-cholesterol diet, have been found to reduce cardiovascular disease (CVD) risk, in addition to potentially improving serum lipid profiles, decreasing low-density lipoprotein (LDL) oxidation, and exerting a cardio protective effect $[8,9]$. The antioxidant components in vegetable oils are composed of hydrocarbons, carotenes, tocopherol, phytosterols, and triterpenes; the minor constituents of various vegetable oils are associated with medicinal qualities and thus can be useful in preventing or delaying the onset of chronic diseases and promoting health $[9,10]$.

Organic solvent extraction (mostly using petroleum ether, petroleum benzene, and hexane) and mechanical pressing are two conventionally used commercial methods of producing vegetable oils. However, the residual solvent that remains of the former process can cause environmental safety issues and neurological damage, while mechanical pressing provides only a low yield of oils [11]. To increase the extractability of oil, several destructive pretreatments need to be performed. Cold-pressed oils are generated with no refining process and have good flavor, stable quality, and are high in bioactive components, qualities that have led them to be regarded as excellent food oils by consumers [12]. Roasting, grinding, and pressing have been the key steps in peanut oil processing. Recent research findings, however, have given rise to the enhancement of substitute processing techniques for oil production and flavor. Roasting constitutes a critical processing stage that affects the color, composition, conversion to bioactive compounds, and organoleptic qualities of the extracted oils, as well as their oxidative stability [13-15]. Research has shown, for example, that roasting increases the oxidative stability of sesame oil, with no oxidation being observed for 50 days after roasting [16].

Roasting is an essential step to peanut oil preparation. However, in Asia, commercial production focuses on the relationship between roasting temperature and aroma but ignores thermal-oxidative degradation and active substance. This study aims to investigate peanuts that were roasted at different temperatures $\left(120,140\right.$, and $\left.160{ }^{\circ} \mathrm{C}\right)$ to determine how those roasting temperatures affect the chemical properties related to the quality of the oils generated. We investigated various quality indices and the oxidative stability of the generated peanut oils, as edible oils have been increasingly recognized as a necessary source of antioxidant components in a healthy balanced diet. In relation to this, the obtained data should be useful for deepening the understanding of the chemical profile, in addition to providing scientific evidence for enhancing the quality of the human diet. Moreover, this present work may serve as a worthy reference for future complementary studies aimed at evaluating the beneficial effects of vegetable oils on human health.

\section{Materials and Methods}

\subsection{Materials}

All chemicals and solvents, including6-hydroxy-2,5,7,8-tetramethylchroman-2carboxylic acid (Trolox), 1,1-diphenyl-2-picrylhydrazyl (DPPH), 2,4,6-Tripyridyl-STriazine (TPTZ), $\alpha$-tocopherol, $\gamma$-tocopherol, gallic acid, quercetin, Folin-Ciocalteu reagent, and fatty acid methyl ester standard mixture, were supplied by Merck (Darmstadt, Germany), Sigma-Aldrich (St. Louis, MO, USA), and CHEMICAL CO., LTD (Miaoli, Taiwan).

\subsection{Production of Peanut Oils}

Samples of peanut were supplied in February 2019 by a marketing cooperative (Chiayi, Taiwan). The peanuts were separated into batches, each batch being weighted separately to $5 \mathrm{~kg}$, and roasted in a roasting machine at $120^{\circ} \mathrm{C}, 140{ }^{\circ} \mathrm{C}$, or $160^{\circ} \mathrm{C}$ for $10 \mathrm{~min}$ individually. 
Then, each sample of the roasted peanut was pressed for its oil using a mechanical pressing machine and, after filtering, the oil was collected.

\subsection{Fatty Acid and Quality Indicesanalysis}

The fatty acid composition of each sample was analyzed through gas chromatography/flame ionization detector (GC/FID) (HP 6890, CA, USA). Following the AOCS official method Ce 2-6616 [17], triacylglycerol was first converted to methyl ester, and then, by using a DB-23 column $(30 \mathrm{~m} \times 0.25 \mathrm{~mm} \times 0.25 \mu \mathrm{m})$ with helium at a flow rate of $1.0 \mathrm{~mL} / \mathrm{min}$, methyl esters were separated. The condition of the oven temperature is as follow: (I) held at $200{ }^{\circ} \mathrm{C}$ for $8 \mathrm{~min}$ in the beginning, (II) increased to $220^{\circ} \mathrm{C}$ (speed of $10{ }^{\circ} \mathrm{C} / \mathrm{min}$ ), then held for $40 \mathrm{~min}$. The FID and the injector (split mode 1:40, $4 \mathrm{~mm}$ liner) was maintained at $270{ }^{\circ} \mathrm{C}$ and $250{ }^{\circ} \mathrm{C}$, respectively. Quantification was carried out using the normalization method. For each oil sample, the determination of quality indices, including the acidity value $(\mathrm{AV})$, peroxide value $(\mathrm{POV})$, anisidine value $(\mathrm{p}-\mathrm{AV})$, and color, was performed. The $\mathrm{AV}(\mathrm{mg} \mathrm{KOH} / \mathrm{g}$ ) was measured by titration using $0.1 \mathrm{~N} \mathrm{KOH} /$ alcoholic solution. The POV (meq/Kg) was measured using a titration with $0.01 \mathrm{~N}$ sodium thiosulfate solution. The $\mathrm{p}-\mathrm{AV}$ was measured using $0.25 \%$ anisidine/glacical acetic acid by UV absorbance at $350 \mathrm{~nm}$. The total oxidation (TOTOX) value was then calculated using the formula $\mathrm{AV}+2 \mathrm{POV}$ to define the given oil sample's overall oxidation state. The color analysis was carried out using UV-light absorption and the browning index (BI), according to previous research [18].

\subsection{Antioxidant Components and Antioxidant Capacity Analysis}

Tocopherol analysis was performed by HPLC, as described previously, using Hitachi instruments (Hitachi, Tokyo, Japan) equipped with a C18-Varian column $(25 \mathrm{~cm} \times 4 \mathrm{~mm}$; Kanto Chemical Co., Inc., Tokyo, Japan), and detection was applied using a UV detector at $298 \mathrm{~nm}$ [12]. The calibration curves of each standard were respectively initiated by plotting peak area versus the corresponding concentration. Phytosterol analysis was performed by GC/MS, as described previously, using an Agilent instrument equipped with a DB-1 column ( $60 \mathrm{~m} \times 0.25 \mathrm{~mm}$ i.d.; Agilent, Palo Alto, CA, USA) [19]. The $5 \alpha$-cholesterol was taken as an internal standard, and the ratio of the peak area of the analytic and internal standard was used as an analytical signal.

The total phenolic and total flavonoid contents were analyzed using the method mentioned in previous literature [12]. Each oil sample (5 g) was mixed with acetone/methanol $(2: 8)$ to $50 \mathrm{~mL}$. The total phenolic content and total flavonoid content of the oil samples were evaluated by the methods described in previous literature [18]. The antioxidant activity of each peanut oil sample was evaluated using the biochemical methods of DPPH and Ferric ion reducing antioxidant power (FRAP) assays. The DPPH radical-clearing capacity was measured following previous research [20]. Each oil sample was diluted with acetone/methanol (2:8) to concentrations of $1 \mathrm{mg} / \mathrm{mL}$, and then mixed together with a methanol solution of DPPH radical $(0.2 \mathrm{mM})$. After vigorous shaking, the mixture was incubated at room temperature for $30 \mathrm{~min}$, and then absorbance was measured at $517 \mathrm{~nm}$. The FRAP was measured following the method used in previous research [21]. Each oil sample was diluted with acetone/methanol (2:8) to concentrations of $2 \mathrm{mg} / \mathrm{mL}$, and was then mixed with FRAP reagent (acetate buffer, $\mathrm{FeCl}_{3}$ solution, and TPTZ; 10:1:1). After vigorous shaking, the mixture was incubated at room temperature for $10 \mathrm{~min}$, and then absorbance was measured at $595 \mathrm{~nm}$. Trolox was used as the positive control.

\subsection{Volatile Compound Analysis}

The volatile compounds were extracted using solid phase microextraction (SPME) with Divinylbenzene/Carboxen/Polydimethylsiloxane (DVB/CAR/PDMS) (Supelco, Inc., Bellefonte, PA, USA) fiber following previously described methods [22]. Individual oil samples ( $5 \mathrm{~g}$ ) were chosen and placed into a sealed bottle and were then immediately placed in a water bath at $50^{\circ} \mathrm{C}$. The aroma compounds were extracted using the SPME 
method for $30 \mathrm{~min}$. The fiber was then removed and transferred into the GC/MS injector for the GC/MS measurements; a GC HP 6890 (CA, USA) attached to an HP5973MSD detector with a DB- 1 column $(60 \mathrm{~m} \times 0.25 \mathrm{~mm} \times 0.25 \mu \mathrm{m}$, Agilent, Palo Alto, CA, USA $)$ was used. Helium was operated at a flow rate of $1 \mathrm{~mL} / \mathrm{min}$. The ionization potential used was $70 \mathrm{eV}$, and the temperature of the ion source was at $230^{\circ} \mathrm{C}$. The condition of the oven temperature was as follows: (I) $40{ }^{\circ} \mathrm{C}$ as the initial temperature, then increased to $120^{\circ} \mathrm{C}$ (speed of $3{ }^{\circ} \mathrm{C} / \mathrm{min}$ ) and (II) then set to a rate of increase to $200{ }^{\circ} \mathrm{C}$ (speed of $5{ }^{\circ} \mathrm{C} / \mathrm{min}$ ), which was then held for $10 \mathrm{~min}$. The linear retention indices (RIs) were calculated from the retention times of $n$-alkanes $\left(\mathrm{C}_{5}-\mathrm{C}_{25}\right)$, and the volatiles were identified by matching the retention indices (RI) with data found in other literature. The quantities of volatile compounds were indicated using the peak area.

\subsection{Kinetic Parameters of Rancimat Test}

Using a Rancimat 743 apparatus, oil samples ( $5 \mathrm{~g})$ were tested for oxidative stability at 5 different temperatures $\left(100,105,110,115\right.$, and $\left.120^{\circ} \mathrm{C}\right)$. The induction periods (IPs)(hours), which are used as a measurement of oxidative stability, were automatically recorded at an air flow rate of $10 \mathrm{~L} / \mathrm{h}$, and the intersected point of two extrapolated parts of the curves were taken as the IPs of each sample.

The samples' kinetic parameters were established by following previously described methods [23]. Kinetic rate constant, temperature coefficients ( $\mathrm{T}$ Coeff, $\left.\mathrm{K}^{-1}\right)$, activation energies $\left(E_{\mathrm{a}}, \mathrm{kJ} / \mathrm{mol}\right)$, and pre-exponential or frequency factors $\left(\mathrm{A}, \mathrm{h}^{-1}\right)$ were defined by methods described in previous literature [12].

\subsection{Statistical Analysis}

The data reported were obtained from triplicate measurements of the samples. The results were analyzed by one-way analysis of variance (ANOVA) using SAS 9.0 (SAS Inst., Cary, NC, USA), and $p<0.05$ was considered statistically significant. In addition, the data were analyzed using principal component analysis (PCA) combined with VARIMAX rotation. XLSTAT software (version 2010.2.01, Add in soft Deutschland, Andernach, Germany) was used for PCA analysis.

\section{Results and Discussion}

\subsection{Quality Indices}

The high temperature used in roasting can promote lipid oxidation, which in turn influences the quality of the peanut oil [24]. The visual appearance of peanut oil changes from a dark yellow to red brown as roasting temperature is increased. Simultaneously, the results show that the browning index (BI) of the peanut oils generated by different roasting temperatures in this study ranged from 37.94 195.71 (Table 1). Furthermore, the AVs of the peanut oils generated by different roasting temperatures ranged from $1.12 \sim 1.94 \mathrm{mg}$ $\mathrm{KOH} / \mathrm{g}$, while the POVs of the peanut oils generated by different roasting temperatures ranged from 5.48 8.67 meq peroxide $/ \mathrm{kg}$. These values meet the Chinese National Standard criteria for peanut oil ( $\mathrm{AV}<2.0 \mathrm{mg} \mathrm{KOH} / \mathrm{g}$ and $\mathrm{POV}<10$ meq peroxide/ $\mathrm{kg}$ ). $\mathrm{AV}$ and $\mathrm{POV}$ determinations are often used as general indications of the condition and edibility of oils. When an oil has a POV $>10$ meq peroxide $/ \mathrm{kg}$, it is less stable and is more likely to have a short shelf life [25]. Relatedly, oxidation products can cause undesirable health problems. The result show that the $\mathrm{p}-\mathrm{AVs}$ of the peanut oils were generated by different roasting temperatures ranging from 5.47 10.42 meq $/ \mathrm{kg}$. We further found that the TOTOX values of the peanut oils generated by roasting at $120^{\circ} \mathrm{C}, 140{ }^{\circ} \mathrm{C}$, and $160^{\circ} \mathrm{C}$ were $16.43,26.70$, and 27.76, respectively. The quality standards of the European Pharmacopoeia require specific levels of TOTOX $\leq 30$. 
Table 1. Quality indices in peanut oils was influenced by roasting temperatures.

\begin{tabular}{cccc}
\hline & \multicolumn{3}{c}{ Peanut Oil Roasted At } \\
\cline { 2 - 4 } & $\mathbf{1 2 0}{ }^{\circ} \mathbf{C}$ & $\mathbf{1 4 0}{ }^{\circ} \mathbf{C}$ & $\mathbf{1 6 0}{ }^{\circ} \mathbf{C}$ \\
\hline BI & $37.94 \pm 1.96$ & $62.39 \pm 4.58$ & $195.71 \pm 9.61$ \\
POV & $5.48 \pm 0.34$ & $7.13 \pm 0.56$ & $8.67 \pm 0.44$ \\
AV & $1.12 \pm 0.14$ & $1.74 \pm 0.21$ & $1.94 \pm 0.24$ \\
p-AV & $5.47 \pm 0.69$ & $12.44 \pm 1.15$ & $10.42 \pm 0.96$ \\
TOTOX & $16.43 \pm 1.34$ & $26.70 \pm 2.33$ & $27.76 \pm 1.98$ \\
\hline
\end{tabular}

Data presented are in mean \pm SD form $(n=3)$ : BI, browning index; POV, peroxide value (meq peroxide $/ \mathrm{kg}$ ); $\mathrm{AV}$, acid value (mg KOH/g); $\mathrm{p}-\mathrm{AV}$, anisidine value (meq $/ \mathrm{kg}$ ); TOTOX, total oxidation value (meq/ $\mathrm{kg}$ ).

Various fatty acids influence the nature of an oil's physicochemical and nutritional performance. Regarding the fatty acid compositions of the peanut oils generated after roasting in this study, we found eight types of fatty acids. The obtained data further showed that there was no significant difference in fatty acid composition for the oils generated by different roasting temperatures (Table $2, p<0.05$ ). Oleic acid is an important nutritional component of peanut oil. Compared with PUFA, oleic acid is more resistant to thermal oxidation, both at ambient storage temperatures and at the high temperatures that prevail during cooking and frying of food [26,27]. Similarly, vegetable oils with higher unsaturated fatty acid/saturated fatty acids (U/S) ratios are more precious in terms of nutritional quality, as they may contribute to a greater extent to lowering the LDL cholesterol and total cholesterol of people, while not affecting their levels of beneficial High-density lipoprotein (HDL) cholesterol $[8,28]$. We found that the U/S values of the peanut oils generated by roasting in this study ranged from 3.58 3.68. Other studies have indicated that the U/S values of camellia seed oils ranged from 3.23 3.31 [18].

Table 2. Fatty acid compositions (\%) in peanut oils was influenced by roasting temperatures.

\begin{tabular}{cccc}
\hline & & Peanut Oil Roasted At & \\
\cline { 2 - 4 } & $\mathbf{1 2 0}{ }^{\circ} \mathbf{C}$ & $\mathbf{1 4 0}^{\circ} \mathbf{C}$ & $\mathbf{1 6 0}{ }^{\circ} \mathbf{C}$ \\
\hline C16:0 & $14.36 \pm 0.06$ & $13.68 \pm 0.04$ & $14.18 \pm 0.06$ \\
C18:0 & $3.01 \pm 0.01$ & $3.07 \pm 0.02$ & $3.63 \pm 0.02$ \\
C18:1 & $37.23 \pm 0.15$ & $36.67 \pm 0.20$ & $38.44 \pm 0.11$ \\
C18:2 & $40.65 \pm 0.24$ & $40.80 \pm 0.19$ & $39.00 \pm 0.21$ \\
C20:0 & $1.25 \pm 0.01$ & $1.53 \pm 0.02$ & $1.29 \pm 0.01$ \\
C20:1 & $0.75 \pm 0.01$ & $0.83 \pm 0.01$ & $0.73 \pm 0.01$ \\
C22:0 & $2.00 \pm 0.03$ & $2.48 \pm 0.01$ & $2.10 \pm 0.01$ \\
C24:0 & $0.75 \pm 0.01$ & $0.94 \pm 0.01$ & $0.64 \pm 0.01$ \\
U/S & $3.68 \pm 0.01$ & $3.61 \pm 0.02$ & $3.58 \pm 0.02$
\end{tabular}

Data presented are in mean \pm SD form $(n=3)$. U/S: unsaturated fatty acid/saturated fatty acid.

\subsection{Antioxidant Components Change}

Lipid oxidation results in undesirable taste and flavor, and oils with high levels of lipid oxidation may lose nutritional value and generate toxic compounds [18,27]. Antioxidant components in oils are thus important with respect to their dietary effects when consumed by humans. Past literature has reported that the natural antioxidant activity of refined oil may be lower than that of crude oil [28]. The result show that the $\alpha$-tocopherol levels of the peanut oils generated by roasting at $120^{\circ} \mathrm{C}, 140^{\circ} \mathrm{C}$, and $160^{\circ} \mathrm{C}$ significantly decreased from 72.33 to $55.72 \mu \mathrm{g} / \mathrm{g}$; their $\gamma$-tocopherol contents did not significantly change. Related research has shown that $\gamma$-tocopherol had better antioxidant capacity and thermal stability than $\alpha$-tocopherol [12]; their total phenolic contents increased from 18.31 to $36.61 \mathrm{GAE} \mu \mathrm{g} / \mathrm{g}$, respectively; their total flavonoid contents did not significantly change (Table 3). In analyzing the phytosterol derivatives of the peanut oils, we identified squalene, campesterol, stigmasterol, stigmast-5-en-3-ol, and stigmasta-5,24(28)-dien-3-ol. The results further showed 
that, as the roasting temperatures of the peanut oils increased, the levels of squalene, campesterol, stigmasterol, and stigmast-5-en-3-ol contained in the oils also increased.

Table 3. Antioxidant components and antioxidant capacity in peanut oils was influenced by roasting temperatures.

\begin{tabular}{|c|c|c|c|}
\hline & \multicolumn{3}{|c|}{ Peanut Oil Roasted at } \\
\hline & $120^{\circ} \mathrm{C}$ & $140{ }^{\circ} \mathrm{C}$ & $160{ }^{\circ} \mathrm{C}$ \\
\hline \multicolumn{4}{|c|}{ Antioxidant Components } \\
\hline$\alpha$-tocopherol $(\mu \mathrm{g} / \mathrm{g})$ & $72.33 \pm 3.24^{c}$ & $60.39 \pm 3.64^{b}$ & $55.72 \pm 2.84^{\mathrm{a}}$ \\
\hline$\gamma$-tocopherol $(\mu \mathrm{g} / \mathrm{g})$ & $67.31 \pm 2.48^{a}$ & $72.91 \pm 3.11^{\mathrm{a}}$ & $70.51 \pm 3.18^{a}$ \\
\hline squalene1 $(\mu \mathrm{g} / \mathrm{g})$ & $8.58 \pm 1.83^{\mathrm{a}}$ & $9.15 \pm 1.41^{\mathrm{ab}}$ & $13.31 \pm 2.52^{b}$ \\
\hline campesterol $(\mu \mathrm{g} / \mathrm{g})$ & $2.48 \pm 1.17^{\mathrm{a}}$ & $2.51 \pm 0.73^{\mathrm{a}}$ & $3.20 \pm 0.89^{b}$ \\
\hline stigmasterol $(\mu \mathrm{g} / \mathrm{g})$ & $2.55 \pm 0.19^{a}$ & $2.01 \pm 0.22^{a}$ & $2.88 \pm 0.17^{b}$ \\
\hline stigmast-5-en-3-ol ( $\mu \mathrm{g} / \mathrm{g})$ & $7.34 \pm 0.34^{\mathrm{a}}$ & $6.73 \pm 0.55^{\mathrm{a}}$ & $10.23 \pm 0.48^{b}$ \\
\hline stigmasta-5,24(28)-dien-3-ol ( $\mu \mathrm{g} / \mathrm{g})$ & $2.72 \pm 0.11^{\mathrm{a}}$ & $2.27 \pm 0.20^{\mathrm{a}}$ & $2.23 \pm 0.16^{\mathrm{a}}$ \\
\hline total phenol $(\mathrm{GAE} \mu \mathrm{g} / \mathrm{g})$ & $18.31 \pm 1.03^{\mathrm{a}}$ & $29.63 \pm 1.62^{b}$ & $36.64 \pm 2.83^{c}$ \\
\hline total flavonoid (QE $\mu \mathrm{g} / \mathrm{g})$ & $4.27 \pm 0.15^{\mathrm{a}}$ & $3.96 \pm 0.19^{\mathrm{a}}$ & $4.44 \pm 0.21^{\mathrm{a}}$ \\
\hline \multicolumn{4}{|c|}{ Antioxidant Capacity } \\
\hline DPPH $(\%)$ & $42.02 \pm 1.35^{\mathrm{a}}$ & $47.97 \pm 1.26^{b}$ & $52.34 \pm 1.96^{\mathrm{c}}$ \\
\hline FRAP (TrE $\mu g / g)$ & $151.22 \pm 12.62^{\mathrm{a}}$ & $250.52 \pm 20.38^{b}$ & $328.64 \pm 26.14^{c}$ \\
\hline
\end{tabular}

The data presented are in the mean \pm SD form $(n=3)$, with different letters indicating values that are significantly different at $p<0.05$.

The antioxidants in oils improve their oxidative stability and prevent their oxidative degradation, either by delaying the oxidation reaction by reacting with free radicals or by inhibiting the propagation step by reacting with alkoxy and alkyl peroxy radicals [29]. The results of this study further showed the DPPH clearing capacity of $2.5 \%$ peanut oil was 42.02 52.34\%, while the FRAP was 151.22 328.64 Trolox $\mu \mathrm{g} / \mathrm{g}$ (Table 3.). The oil generated by roasting at $160{ }^{\circ} \mathrm{C}$ had the best antioxidant capacity among the three varieties. Roasting could increase the release of phenols by the bound phenolic compounds of the peanut's brown skin and the formation of Maillard reaction products such as melanoidins [14,15]. These substances protect tocopherols from heat degradation during roasting. However, while phytosterols are important, the interactions between the antioxidants have synergistic effects [26].

The olfactory sensations of edible oils are very important, and these sensations combine the effects of an oil's constituents on the taste and olfactory organs. The processing techniques used in producing oils would significantly affect the major volatile component concentrations, and hence determine their flavor quality. In this study, we detected 20 volatile compounds in the peanut oils generated by different roasting temperatures, including $7 \mathrm{~N}$-heterocyclic compounds, 5 alkane compounds, 4 O-heterocyclic compounds, and 2 aldehyde compounds, as well as alcohol and sulfide (Table 4). Roasting affects the production of volatile compounds, particularly those derived from $\mathrm{N}$-heterocyclic compounds (such as pyrazine and pyrrole), with the formation of alkylated pyrazines occurring via automatic condensation or condensation with other aminoketones of $\alpha$-aminoketones in the Strecker degradation [30,31]. Peanuts contain abundant amounts of essential precursors for the Maillard reaction, and the carbon skeleton of the pyrazines is derived in the Maillard reaction from carbohydrate degradation, while the pyrazinic nitrogen originates directly from amino acids [30,31]. We found that some volatile compounds were formed during lipid oxidation, with dioxygen leading to the formation of hexanal, 2-hepten-1-ol, and nonanal. Hexanal emerged from linoleic acid, whereas nonanal is an oleic acid derivative that mainly imparts a fresh and fatty flavor [32]. The results showed that high roasting temperatures $\left(160^{\circ} \mathrm{C}\right)$ induce the formation of volatile compounds through the Maillard reaction and lipid oxidation. In particular, high roasting temperatures result in the removal of 2,3,4-trithiapentane, helping to prevent foul odors. 
Table 4. Volatile compounds (\%) in peanut oils was influenced by roasting temperatures.

\begin{tabular}{|c|c|c|c|c|}
\hline \multirow{2}{*}{ Compound } & \multirow{2}{*}{ RI } & \multicolumn{3}{|c|}{ Peanut Oil Roasted at } \\
\hline & & $120^{\circ} \mathrm{C}$ & $140^{\circ} \mathrm{C}$ & $160^{\circ} \mathrm{C}$ \\
\hline hexanal & 778 & 9.86 & 9.11 & 9.49 \\
\hline 2-methylpyrazine & 794 & 20.65 & 38.31 & 26.61 \\
\hline fruanmethanol & 844 & 3.8 & 2.45 & 0.89 \\
\hline methylbutyloxirane & 878 & 2.17 & 1.06 & 0.53 \\
\hline 3,5-dimethylcyclohexene & 882 & 1.43 & 1.7 & 1.32 \\
\hline 2,5-dimethylpyrazine & 884 & 21.39 & 23.33 & 20.86 \\
\hline benzaldehyde & 925 & 6.58 & 4.53 & 3.19 \\
\hline 2,3,4-trithiapentane & 942 & 0.38 & 0.38 & 0.13 \\
\hline 2-hepten-1-ol & 948 & 0.42 & 0.15 & 0.26 \\
\hline 2-ethyl-6-methylpyrazine & 964 & 13.61 & 11.39 & 12.15 \\
\hline 2,5-dimethylheotane & 981 & 4.23 & 2.02 & 2.52 \\
\hline benzeneacetaldhyde & 1008 & 10.16 & 1.53 & 0.88 \\
\hline acthylpyrrole & 1032 & ND & 0.07 & 13.69 \\
\hline 2-ethyl-3,5-dimethylpyrazine & 1056 & 2.51 & 2.51 & 3.11 \\
\hline nonanal & 1100 & 1.83 & 0.4 & 0.61 \\
\hline benzeneethanol & 1108 & 0.65 & 0.1 & ND \\
\hline 2-acetyl-3-methylpyrzaine & 1120 & ND & 0.14 & 0.31 \\
\hline undecane & 1132 & 0.33 & 0.46 & 0.38 \\
\hline 3,5-diethyl-2-ethylpyrazine & 1184 & ND & 0.1 & 0.2 \\
\hline tetradecane & 1744 & ND & 0.26 & 2.87 \\
\hline
\end{tabular}

Data present are in mean \pm SD form $(n=3)$. ND: not detected.

\subsection{Oxidation Stability}

The oxidation process accelerates the Rancimat test by disclosing oil samples to high temperature and high oxygen solubility, and that in turn determines the induction period for the formation of volatile acids [33]. In this study, we investigated the oxidative stability of the peanut oils generated using the Rancimat test at temperatures of $100 \sim 120{ }^{\circ} \mathrm{C}$ (Figure 1). For the use of the Rancimat test at temperature of $100,105,110,115$, and $120^{\circ} \mathrm{C}$, the induction times were $13.58,12.01,8.56,4.89$, and $3.94 \mathrm{~h}$, respectively, for the oils roasted at $120^{\circ} \mathrm{C}$; $20.85,14.15,8.75,5.67$, and $3.68 \mathrm{~h}$, respectively, for the oils roasted at $140^{\circ} \mathrm{C}$; and 21.55 , $15.12,10.87,5.88$, and $3.71 \mathrm{~h}$, respectively, for the oils roasted at $160^{\circ} \mathrm{C}$. Simultaneously, the semi-logarithmic relationship for all the oil samples was calculated using Equation I, including a linear dependency with good correlation of determination, $\mathrm{R}^{2}$ 0.959 0.998, for the different roasting temperatures (Figure 1). The kinetic parameters of the Rancimat test are valuable for the goal of distinguishing between various oils, for characterizing the differences or similarities in oils, and for predicting the oxidative stability of oils under various storage conditions [34]. The $E_{\mathrm{a}}$ values for all the oil samples were determined using Equation II; the bond scission that takes place forming primary oxidation products is shown through the delay of the initial oxidation reaction [35]. Related research has shown that the oxidative stability of peanut oil increased with increased roasting temperature [36]. This study was similar to such results; the $E_{\mathrm{a}}$ values of the assayed oils were $82.08 \mathrm{~kJ} / \mathrm{mol}$ for the oil roasted at $120^{\circ} \mathrm{C}, 105.2 \mathrm{~kJ} / \mathrm{mol}$ for the oil roasted at $140{ }^{\circ} \mathrm{C}$, and $108.61 \mathrm{~kJ} / \mathrm{mol}$ for the oil roasted at $160^{\circ} \mathrm{C}$ (Table 5). Other studies have indicated that the $E_{\mathrm{a}}$ values for vegetable oils ranged from $86.86 \sim 82.42 \mathrm{~kJ} / \mathrm{mol}$. The $E_{\mathrm{a}}$ value of oil is influenced by the level of unsaturated fatty acids and antioxidants present in the oil [18]. 


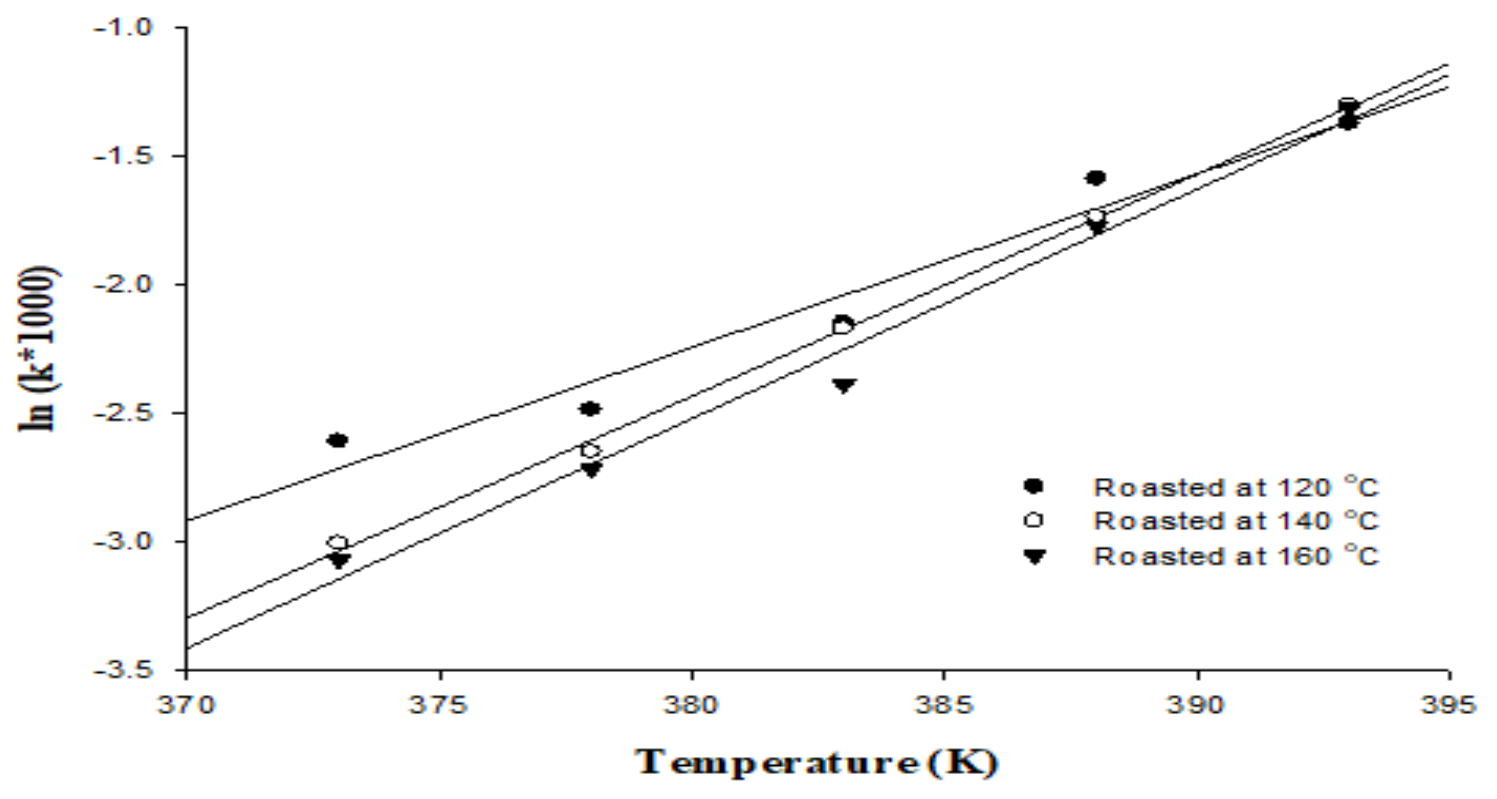

Figure 1. Semi-logarithmic relationship between $\mathrm{k}$ and temperature values for lipid oxidation of peanut oil.

Table 5. Regression parameters for Arrhenius relationships between the reaction rate constant and the temperature for peanut oils.

\begin{tabular}{|c|c|c|c|}
\hline & \multicolumn{3}{|c|}{ Peanut Oil Roasted at } \\
\hline & $120^{\circ} \mathrm{C}$ & $140^{\circ} \mathrm{C}$ & $160^{\circ} \mathrm{C}$ \\
\hline \multicolumn{4}{|c|}{$\ln (\mathrm{k})=\mathrm{a}(1 / \mathrm{T})+\mathrm{b}$} \\
\hline a & -9.8725 & -12.653 & -13.064 \\
\hline $\mathrm{b}$ & 23.74 & 30.87 & 31.87 \\
\hline $\mathrm{R}^{2}$ & 0.956 & 0.997 & 0.983 \\
\hline$E \mathrm{a}(\mathrm{kJ} / \mathrm{mol})$ & 82.08 & 105.2 & 108.61 \\
\hline
\end{tabular}

This study investigated the compound changes and olfactory sensations for peanut oils roasted at different temperatures, which were characterized in terms of oxidative stability by PCA (Figure 2). The key results include the following findings: (1) The $E_{\mathrm{a}}$ values of the oils indicated that their oxidative stability was highly correlated with their levels of total phenol (r: 0.963), DPPH (r: 0.963), FRAP (r: 0.944), and r-tocopherol (r: 0.739). The occurrence of total phenol and $\gamma$-tocopherol led to a high $E_{\mathrm{a}}$ value in the products, causing high DPPH and FRAP performance simultaneously. (2) The N-heterocyclic compounds in the oils provided an overall indication of their olfactory sensations. In the process of roasting, the oxide (O-heterocyclic ( $\mathrm{r}:-0.986)$, aldehyde $(\mathrm{r}:-0.950)$, and alcohol (r: -0.890)) compounds generated were transformed into $\mathrm{N}$-heterocyclic compounds as the temperature increased due to the Maillard reaction. Other studies have indicated that unrefined oils naturally contain antioxidant compounds that provide oil oxidation stability $[10,18,29]$; especially, polyphenol has an effective approach to mitigating the heatoxidation formation of oxidative free radicals, mainly by inhibiting oxidative pathways and trapping reactive intermediates [14]. 


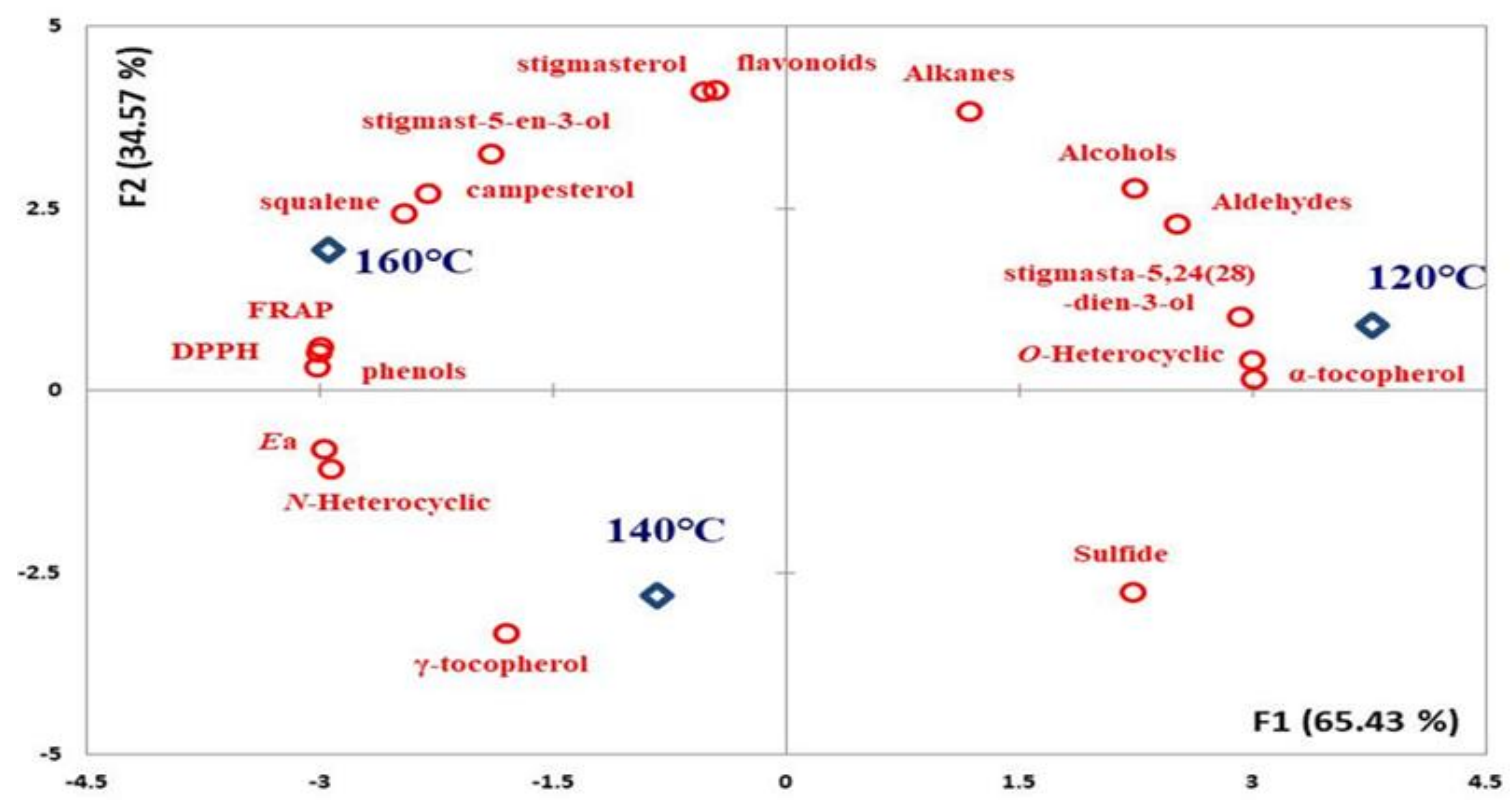

Figure 2. Principal component analysis (PCA) plots of composition change and oxidation stability for peanut oils generated by different roasting temperatures.

\section{Conclusions}

The results obtained in this study provide consumers with important information regarding the qualities of roasted peanut oils. The major findings were as follows: (I) The tested peanut oils were rich in antioxidant components including tocopherol, phytosterol, phenolic, and flavonoid. These compounds can not only promote health, but also improve oxidation stability, which prolongs the shelf life of the peanuts oil. (II) The olfactory sensations of the tested oils were positively correlated with the temperatures at which they were roasted. (III) High oxidative stability prevents oxidation and deterioration. The obtained data should be useful for deepening the understanding of the chemical composition of peanut oils, in addition to providing scientific evidence for improving the quality of human diets.

Author Contributions: J.-Y.C., H.-C.C., and K.-M.Y. carried out all the experiments; J.-Y.C., H.-C.C., C.-W.C., and K.-M.Y. designed all the experiments and analyzed the data; J-Y.C. and K.-M.Y. wrote the manuscript. All authors have read and agreed to the published version of the manuscript.

Funding: Financial support from MOST 106-2632-B-241-001, from the Ministry of Science and Technology (Taiwan, ROC).

Institutional Review Board Statement: No applicable.

Informed Consent Statement: No applicable.

Data Availability Statement: No applicable.

Conflicts of Interest: The authors declare no conflict of interest.

\section{Abbreviations}

The following abbreviations are used in this manuscript:

PCA principal component analysis

SFA saturated fatty acid

MUFA monounsaturated fatty acid

PUFA polyunsaturated fatty acid

U/S unsaturated fatty acid/saturated fatty acids

CVD cardiovascular disease 


$\begin{array}{ll}\text { LDL } & \text { low-density lipoprotein } \\ \text { GC/FID } & \text { gas chromatography/flame ionization detector } \\ \text { HPLC } & \begin{array}{l}\text { high performance liquid chromatography } \\ \text { solid phase microextraction }\end{array} \\ \text { SPME } & \text { Divinylbenzene/Carboxen/Polydimethylsiloxane } \\ \text { DVB/CAR/PDMS } & \text { browning index } \\ \text { BI } & \text { induction period } \\ \text { IP } & \text { activation energies } \\ E_{\text {a }} & \text { peroxide value } \\ \text { POV } & \text { anisidine value } \\ \text { p-AV } & \text { acid value } \\ \text { AV } & \text { total oxidation value } \\ \text { TOTOX } & \text { 1,1-diphenyl-2-picrylhydrazylFRA } \\ \text { DPPH } & \text { Ferric ion reducing antioxidant power } \\ \text { FRAP } & \text { 2,4,6-Tripyridyl-S-Triazine } \\ \text { TPTZ } & \text { gallic acid equivalents } \\ \text { GAE } & \text { quercetin equivalents } \\ \text { QE } & \text { retention indices } \\ \text { RI } & \end{array}$

\section{References}

1. Athar, M.; Nasir, S.M. Taxonomic perspective of plant species yielding vegetable oils used in cosmetics and skin care products. J. Biotechnol. 2005, 4, 36-44.

2. Kornsteiner, M.; Wagner, K.H.; Elmadfa, I. Tocopherols and total phenolics in 10 different nut types. Food Chem. 2006, 98, $381-387$. [CrossRef]

3. Arya, S.S.; Salve, A.R.; Chauhan, S. Peanuts as functional food: A review. J. Food Sci. Technol. 2016, 53, 31-41. [CrossRef]

4. Nawade, B.; Mishra, G.P.; Radhakrishnan, T.; Dodia, S.M.; Ahmad, S.; Kumar, A.; Kundu, R. High oleic peanut breeding: Achievements, perspectives, and prospects. Trends Food Sci. Technol. 2018, 78, 107-119. [CrossRef]

5. Chukwumah, Y.; Walker, L.; Vogler, B.; Verghese, M. Changes in the phytochemical composition and profile of raw, boiled, and roasted peanuts. J. Agric. Food Chem. 2007, 55, 9266-9273. [CrossRef] [PubMed]

6. Liu, K.; Liu, Y.; Chen, F. Effect of gamma irradiation on the physicochemical properties and nutrient contents of peanut. LWT 2018, 96, 535-542. [CrossRef]

7. Xie, Y.; Jiang, S.; Li, M.; Guo, Y.; Cheng, Y.; Qian, H.; Yao, W. Evaluation on the formation of lipid free radicals in the oxidation process of peanut oil. LWT 2019, 104, 24-29. [CrossRef]

8. Hashempour-Baltork, F.; Torbati, M.; Azadmard-Damirchi, S.; Savage, G.P. Vegetable oil blending: A review of physico-chemical, nutritional and health effects. Trends Food Sci. Technol. 2016, 57, 52-58. [CrossRef]

9. Chen, C.Y.O.; Blumberg, J.B. Phytochemical composition of nuts. Asia Pac. J. Clin. Nutr. 2008, 17, 329-332. [PubMed]

10. Alasalvar, C.; Bolling, B.W. Review of nut phytochemicals, fat-soluble bioactives, antioxidant components and health effects. Br. J. Nutr. 2015, 113, S68-S78. [CrossRef]

11. Mingyai, S.; Srikaeo, K.; Kettawan, A.; Singanusong, R.; Nakagawa, K.; Kimura, F.; Ito, J. Effects of extraction methods on phytochemicals of rice bran oils produced from colored rice. J. Oleo Sci. 2018, 67, 135-142. [CrossRef] [PubMed]

12. Yang, K.M.; Chiang, P.Y. Variation quality and kinetic parameter of commercial n-3 PUFA-rich oil during oxidation via Rancimat. Mar. Drugs 2017, 15, 97. [CrossRef] [PubMed]

13. Chang, S.K.; Alasalvar, C.; Bolling, B.W.; Shahidi, F. Nuts and their co-products: The impact of processing (roasting) on phenolics, bioavailability, and health benefits-A comprehensive review. J. Funct. Foods 2016, 26, 88-122.

14. Taş, N.G.; Gökmen, V. Phenolic compounds in natural and roasted nuts and their skins: A brief review. Curr. Opin. Food Sci. 2017, 14, 103-109. [CrossRef]

15. Różańska, M.B.; Kowalczewski, P.Ł.; Tomaszewska-Gras, J.; Dwiecki, K.; Mildner-Szkudlarz, S. Seed-Roasting Process Affects Oxidative Stability of Cold-Pressed Oils. Antioxidants 2019, 8, 313. [CrossRef]

16. Rostami, M.; Farzaneh, V.; Boujmehrani, A.; Mohammadi, M.; Bakhshabadi, H. Optimizing the extraction process of sesame seed's oil using response surface method on the industrial scale. Ind. Crop. Prod. 2014, 58, 160-165. [CrossRef]

17. AOCS. AOCS Official Method Ce 2-66: Preparation of methyl esters of fatty acids. In Official Methods and Recommended Practices of the American Oil Chemists' Society, 5th ed.; Firestone, D., Ed.; American Oil Chemists' Society: Champaign, IL, USA, 1997.

18. Yang, K.M.; Hsu, F.L.; Chen, C.W.; Hsu, C.L.; Cheng, M.C. Quality Characterization and Oxidative Stability of Camellia Seed Oils Produced with Different Roasting Temperatures. J. Oleo Sci. 2018, 67, 389-396. [CrossRef] [PubMed]

19. Han, J.; Yang, Y.; Feng, M. Contents of phytosterols in vegetables and fruits commonly con-sumed in China. Biomed. Environ. Sci. 2008, 21, 449-453. [CrossRef]

20. Lin, L.Y.; Chuang, C.H.; Chen, H.C.; Yang, K.M. Lime (Citrus aurantifolia (Christm.) Swingle) Essential Oils: Volatile Com-pounds, Antioxidant Capacity, and Hypolipidemic Effect. Foods 2019, 8, 398. [CrossRef] [PubMed] 
21. Fernández-Arroyo, S.; Rodríguez-Medina, I.C.; Beltrán-Debón, R.; Pasini, F.; Joven, J.; Micol, V.; Segura-Carretero, A.; Fer-nándezGutiérrez, A. Quantification of the polyphenolic fraction and in vitro antioxidant and in vivo anti-hyperlipemic activities of Hibiscus sabdariffa aqueous extract. Food Res. Int. 2011, 44, 1490-1495. [CrossRef]

22. Yang, K.M.; Cheng, M.C.; Chen, C.W.; Tseng, C.Y.; Lin, L.Y.; Chiang, P.Y. Characterization of volatile compounds with HS-SPME from oxidized n-3 PUFA rich oils via Rancimat tests. J. Oleo Sci. 2017, 66, 113-122. [CrossRef] [PubMed]

23. Farhoosh, R.; Niazmand, R.; Rezaei, M.; Sarabi, M. Kinetic parameter determination of vegetable oil oxidation under Ranci-mat test conditions. Eur. J. Lipid Sci. Technol. 2008, 110, 587-592. [CrossRef]

24. Al Juhaimi, F.; Ghafoor, K.; Babiker, E.E.; Özcan, M.M.; Aadiamo, O.Q.; Alsawmahi, O.N. Influence of Storage and Roasting on the Quality Properties of Kernel and Oils of Raw and Roasted Peanuts. J. Oleo Sci. 2018, 67, 755-762. [CrossRef] [PubMed]

25. Madhujith, T.; Sivakanthan, S. Oxidative Stability of Edible Plant Oils. Bioact. Mol. Food 2018, 7, 1-23.

26. Xu, T.T.; Li, J.; Fan, Y.W.; Zheng, T.W.; Deng, Z.Y. Comparison of oxidative stability among edible oils under continuous frying conditions. Int. J. Food Prop. 2015, 18, 1478-1490. [CrossRef]

27. Peng, C.Y.; Lan, C.H.; Lin, P.C.; Kuo, Y.C. Effects of cooking method, cooking oil, and food type on aldehyde emissions in cooking oil fumes. J. Hazard. Mater. 2017, 324, 160-167. [CrossRef] [PubMed]

28. Cicero, N.; Albergamo, A.; Salvo, A.; Bua, G.D.; Bartolomeo, G.; Mangano, V.; Dugo, G. Chemical characterization of a variety of cold-pressed gourmet oils available on the Brazilian market. Food Res Int. 2018, 109, 517-525. [CrossRef]

29. Redondo-Cuevas, L.; Castellano, G.; Torrens, F.; Raikos, V. Revealing the relationship between vegetable oil composition and oxidative stability: A multifactorial approach. J. Food Compos. Anal. 2018, 66, 221-229. [CrossRef]

30. Dun, Q.; Yao, L.; Deng, Z.; Li, H.; Li, J.; Fan, Y.; Zhang, B. Effects of hot and cold-pressed processes on volatile compounds of peanut oil and corresponding analysis of characteristic flavor components. LWT 2019, 112, 107648. [CrossRef]

31. Siegmund, B.; Murkovic, M. Changes in chemical composition of pumpkin seeds during the roasting process for production of pumpkin seed oil (Part 2: Volatile compounds). Food Chem. 2004, 84, 367-374. [CrossRef]

32. Haiyan, Z.; Bedgood, D.R., Jr.; Bishop, A.G.; Prenzler, P.D.; Robards, K. Endogenous biophenol, fatty acid and volatile profiles of selected oils. Food Chem. 2007, 100, 1544-1551. [CrossRef]

33. Robertson, G.L. Shelf life of packaged foods: Its measurements and prediction. Dev. New Food Prod. Chang. Marketpl. 2000, 329-353.

34. Kochhar, S.P.; Henry, C.J.K. Oxidative stability and shelf-life evaluation of selected culinary oils. Int. J. Food Sci. Nutr. 2009, 60, 289-296. [CrossRef] [PubMed]

35. Farhoosh, R.; Hoseini-Yazdi, S.Z. Evolution of oxidative values during kinetic studies on olive oil oxidation in the Rancimat test. J. Am. Oil Chem. Soc. 2014, 91, 281-293. [CrossRef]

36. Zhang, D.; Li, X.; Cao, Y.; Wang, C.; Xue, Y. Effect of roasting on the chemical components of peanut oil. LWT 2020, 125, 109249. [CrossRef] 